\section{(2) OPEN ACCESS}

\title{
Mitochondrial dysfunction during loss of prohibitin 1 triggers Paneth cell defects and ileitis
}

\author{
Dakota N Jackson, ${ }^{1}$ Marina Panopoulos, ${ }^{1}$ William L Neumann, ${ }^{2}$ Kevin Turner, ${ }^{3}$ \\ Brandi L Cantarel, ${ }^{3}$ LuAnn Thompson-Snipes, ${ }^{1}$ Themistocles Dassopoulos (i), \\ Linda A Feagins, ${ }^{4}$ Rhonda F Souza (1) ${ }^{5}$ Jason C Mills, ${ }^{6}$ Richard S Blumberg, ${ }^{7}$ \\ K Venuprasad, ${ }^{3}$ Winston E Thompson, ${ }^{8}$ Arianne L Theiss (i) ${ }^{1}$
}

\begin{abstract}
- Additional material is published online only. To view please visit the journal online (http://dx.doi.org/10.1136/ gutjnl-2019-319523).

For numbered affiliations see end of article.
\end{abstract}

\section{Correspondence to} Dr Arianne L Theiss, Baylor Scott and White Research Institute, Dallas, TX 75204, USA; arianne.theiss@cuanschutz.edu

Received 23 July 2019 Revised 24 January 2020 Accepted 3 February 2020 Published Online First 28 February 2020

\section{SLinked}

- http://dx.doi.org/10.1136/ gutjnl-2019-319514

\section{Check for updates}

(C) Author(s) (or their employer(s)) 2020. Re-use permitted under CC BY-NC. No commercial re-use. See rights and permissions. Published by BMJ.

To cite: Jackson DN

Panopoulos M, Neumann WL, et al. Gut

2020;69:1928-1938.

\section{ABSTRACT \\ Objective Although perturbations in mitochondrial}

function and structure have been described in the intestinal epithelium of Crohn's disease and ulcerative colitis patients, the role of epithelial mitochondrial stress in the pathophysiology of inflammatory bowel diseases (IBD) is not well elucidated. Prohibitin 1 (PHB1), a major component protein of the inner mitochondrial membrane crucial for optimal respiratory chain assembly and function, is decreased during IBD.

Design Male and female mice with inducible intestinal epithelial cell deletion of $P h b 1\left(P h b 1^{\mathrm{i} \Delta \mathrm{EEC}}\right)$ or Paneth cell-specific deletion of $P h b 1\left(P h b 1^{\triangle P C}\right)$ and $P h b 1^{\mathrm{fl} / f \mathrm{l}}$ control mice were housed up to 20 weeks to characterise the impact of PHB1 deletion on intestinal homeostasis. To suppress mitochondrial reactive oxygen species, a mitochondrial-targeted antioxidant, Mito-Tempo, was administered. To examine epithelial cell-intrinsic responses, intestinal enteroids were generated from crypts of $P h b 1^{i \Delta \mathrm{ECC}}$ or $P h b 1^{\triangle \mathrm{PC}}$ mice.

Results $P h b 1^{\text {i } \triangle \mathrm{EEC}}$ mice exhibited spontaneous ileal inflammation that was preceded by mitochondrial dysfunction in all IECs and early abnormalities in Paneth cells. Mito-Tempo ameliorated mitochondrial dysfunction, Paneth cell abnormalities and ileitis in $P h b 1^{\text {i } \Delta \mathrm{EC}}$ ileum. Deletion of $P h b 1$ specifically in Paneth cells $\left(P h b 1^{\triangle P C}\right.$ ) was sufficient to cause ileitis. Intestinal enteroids generated from crypts of $P h b 1^{\mathrm{i} \Delta \mathrm{IEC}}$ or $P h b 1^{\Delta \mathrm{PC}}$ mice exhibited decreased viability and Paneth cell defects that were improved by Mito-Tempo.

Conclusion Our results identify Paneth cells as highly susceptible to mitochondrial dysfunction and central to the pathogenesis of ileitis, with translational implications for the subset of Crohn's disease patients exhibiting Paneth cell defects.

\section{INTRODUCTION}

Crohn's disease, an inflammatory bowel disease (IBD) characterised by recurring, incurable, chronic inflammation, is considered a global health problem with accelerating incidence in newly industrialized countries and stabilising, yet high prevalence in Western countries. ${ }^{1}$ Crohn's disease is a multifactorial disease exhibiting loss of intestinal epithelial cell (IEC) barrier integrity and dysregulated immune cell responses due to unknown environmental triggers in genetically predisposed

\section{Significance of this study}

What is already known on this subject?

- Previous studies suggest the involvement of epithelial mitochondrial dysfunction in the pathophysiology of inflammatory bowel disease, including Crohn's disease and ulcerative colitis.

What are the new findings?

- We identify Paneth cells as highly susceptible to mitochondrial dysfunction driven by Prohibitin 1 (Phb1) deletion and central to the development of ileitis.

- Treatment of Paneth cell defects with MitoTempo during Phb1 deletion implicates a potential therapeutic application for abnormal Paneth cells via elimination of mitochondrialderived reactive oxygen species.

- Mito-Tempo also prevented the upregulation of interleukin-1 $\beta$ (IL-1 $\beta$ ) and IL-18 in the ileum that were induced early after Phb1 deletion.

- Phb1 deficiency induced loss of viability of the intestinal stem cell niche and Paneth cell defects in cultured enteroids.

How might it impact on clinical practice in the foreseeable future?

- These are the first results that present a causative role of mitochondrial dysfunction in ileitis that initiates in Paneth cells.

- Mitochondrial-targeted therapeutics may have translational utility in a subset of Crohn's disease patients exhibiting Paneth cell defects.

individuals. ${ }^{2}$ Genome-wide association studies have identified $\sim 200$ IBD risk loci, ${ }^{3}$ with $5 \%$ of these genes functionally linked to the maintenance of mitochondrial health. ${ }^{4}$ Mitochondria are dynamic organelles that readily respond to environmental stimuli and cellular demands for energy. Mitochondria are coordinators of cellular homoeostasis via their role in energy production and oxidative metabolism, induction of apoptosis, regulation of calcium, production of reactive oxygen species (ROS), and regulation of signal transduction and epigenomic intermediates. In the intestine, mitochondrial metabolism and function play key roles 
in immune cell activation, IEC barrier integrity and IEC differentiation programmes and stemness. ${ }^{56}$ Previous studies suggest the involvement of epithelial mitochondrial dysfunction in the pathophysiology of IBD, including Crohn's disease and ulcerative colitis, ${ }^{78}$ but whether this is a cause or consequence of the pathogenesis of IBD is not known.

Prohibitin 1 (PHB1) belongs to a family of proteins that share an evolutionarily conserved stomatin/prohibitin/flotillin/HflK/C domain and serves diverse roles in cell function including regulation of cell cycle progression, apoptosis and transcription depending on its subcellular localisation. In IECs, PHB1 predominantly localises to the mitochondria. ${ }^{9}$ PHB1 is the major component protein of the inner mitochondrial membrane (IMM) where it forms a heterodimeric complex with PHB2 to exert chaperon function to stabilise mitochondrial DNA (mtDNA)-encoded proteins and regulate optic atrophy 1 (OPA1)-dependent IMM fusion. ${ }^{10}$ Additionally, PHB1 interacts with and is required for optimal activity of complexes I and IV of the electron transport chain (ETC). ${ }^{10}$ Expression of PHB1 is decreased in mucosal biopsies from IBD-afflicted patients. ${ }^{9} 11$ We previously showed that overexpression of epithelial PHB1 using genetic manipulation (Villin-Phb1 transgenic mice) or therapeutic delivery to the colon decreases oxidative stress and protects mice from experimental colitis. ${ }^{12}{ }^{13}$ Given the known functions of PHB1 in mitochondrial structure and dynamics, we generated three novel mouse models of mitochondrial dysfunction via $P h b 1$ deletion in the intestinal epithelium or specifically in Paneth cells. Here, we investigated the role of IEC mitochondrial dysfunction in intestinal inflammation.

\section{RESULTS}

\section{$P h b j^{\text {iLIEC }}$ mice develop spontaneous ileitis}

Genetic deletion of Phb1 results in embryonic lethality in mice and flies. ${ }^{14}$ To gain tissue and temporal control of PHB1 deletion, we ablated PHB1 in IECs of adult Phb1 floxed mice $\left(P h b 1^{f l}\right.$ ${ }^{f l}$ :Villin-CreERT2 referred to as $P h b 1^{i \Delta I E C}$ mice) by tamoxifen administration. The absence of PHB1 protein in the epithelium was confirmed by western immunoblotting and immunohistochemistry (IHC) staining after tamoxifen injection (online supplementary figure S1). Beginning at 7 weeks after induction of $P h b 1$ deletion, $P h b 1^{\text {i } \triangle E C}$ mice gained less body weight compared with $P h b 1^{f l / f l}$ littermates (online supplementary figure S2A). Within 12 weeks after induction of Phb1 deletion, $P h b 1^{i \Delta I E C}$ mice manifested spontaneous, discontinuous ileal inflammation (figure 1A), while sparing more proximal small intestine and colon (online supplementary figure S2B). Histological alterations in the ileum included infiltration of immune cells,
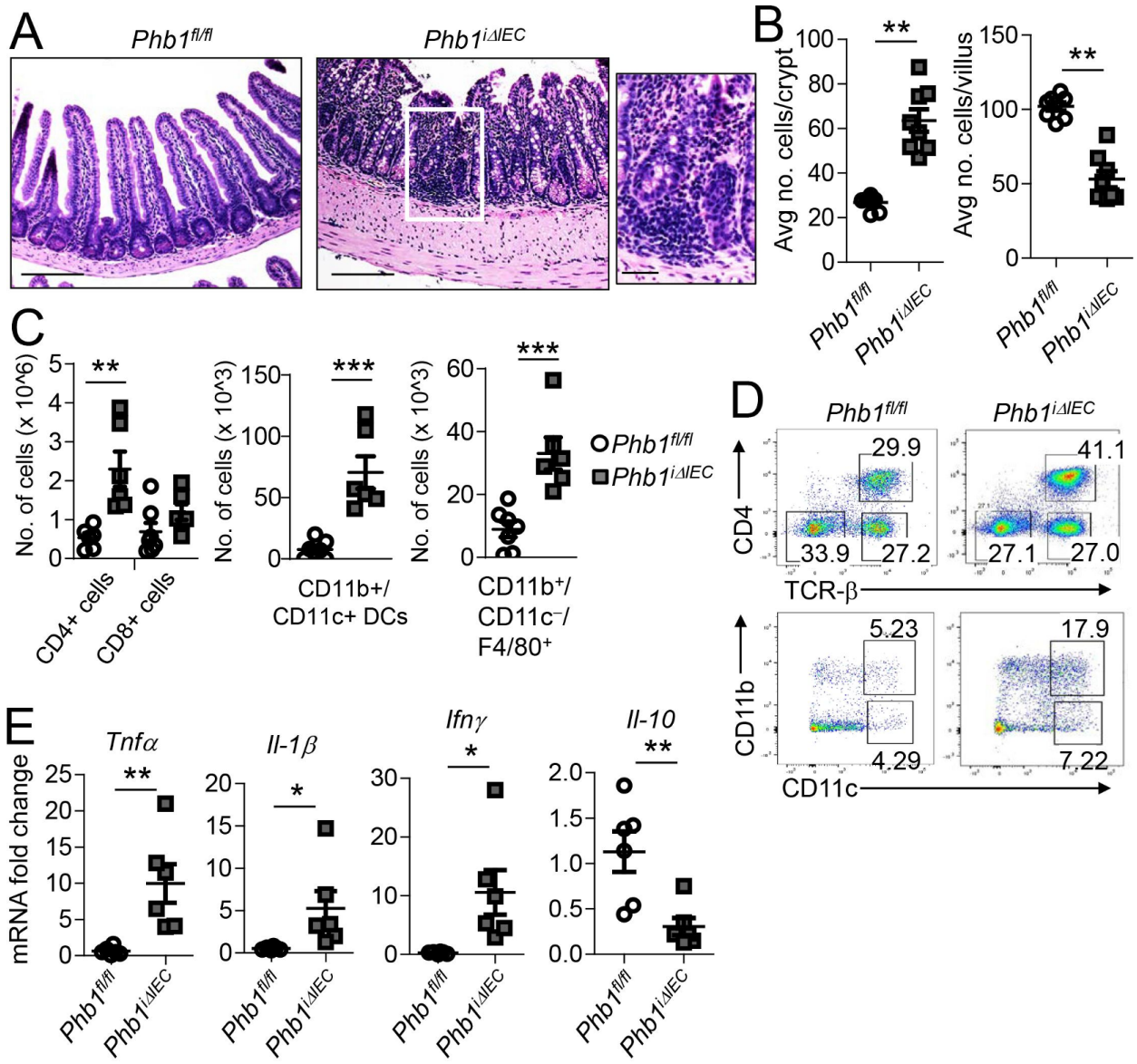

Figure $1 P h b 1^{i \Delta I E C}$ mice develop spontaneous ileitis 12 weeks after Phb1 deletion. (A) H\&E-stained sections showing ileum histology. Scale bars: $250 \mu \mathrm{m}$, boxed pullout: $75 \mu \mathrm{m}$. (B) The number of epithelial cells across 50 crypts or 50 villi per mouse. (C) Absolute number of ileal lamina propria (LP) immune cells calculated of total LP cells isolated from ileum. Data are representative of three independent experiments. (D) Representative flow cytometry plots gated on $\mathrm{CD}_{4} 5^{+}$cells (top) or gated on $\mathrm{CD}^{2} 5^{+} \mathrm{MHCI}{ }^{+} \mathrm{Gr}-1^{-} \mathrm{B} 220^{-}$Cells (bottom) (E) mRNA expression in ileum measured by qPCR. Results are presented as individual data points \pm SEM of 10 mice (B), 6-7 mice (1 Phb1 ${ }^{\text {i } \Delta I E C}$ outlier removed after Grubbs' test) (C), or 6 mice (E) per group. ${ }^{*} \mathrm{P}<0.05,{ }^{*} \mathrm{P}<0.01,{ }^{*}{ }^{*} \mathrm{P}<0.001$ by unpaired, two-tailed Student's t-test. IFN- $\gamma$, interferon- $\gamma$; IL-10, interleukin-10; $P h b 1^{i \Delta I E C}$, intestinal epithelial cell deletion of $P h b 1 ; P h b 1^{\triangle P C}$, Paneth cell-specific deletion of $P h b 1 ;$ TNF $\alpha$, tumour necrosis factor $\alpha$. 
thickening of the muscularis layers, crypt abscesses, crypt architectural changes including crypt branching, crypt elongation, and villus blunting (figure $1 \mathrm{~A}, \mathrm{~B}$, online supplementary figure S2C,D). $P h b 1^{i \Delta I E C}$ mice exhibited splenomegaly and ileal infiltration of $\mathrm{CD}^{+} \mathrm{T}$ cells, CD $11 \mathrm{~b}^{+} / \mathrm{CD} 11 \mathrm{c}^{+}$dendritic cells and $\mathrm{F} 4 / 80^{+}$macrophages (figure $1 \mathrm{C}, \mathrm{D}$, online supplementary figure $\mathrm{S} 2 \mathrm{E})$. Expression of proinflammatory cytokines Tnf $\alpha$, Interleukin- $1 \beta(I L-1 \beta)$ and Interferon- $\gamma(I f n \gamma)$ was increased in Pbb1 $1^{i \Delta I E C}$ ileum with a concomitant decrease in anti-inflammatory $\mathrm{Il}-10$ (figure $1 \mathrm{E}$ ). Gut microbiota was altered in $P h b 1^{i \Delta I E C}$ mice compared with $P h b 1^{f l f l}$ littermates, with decreased bacterial diversity and significant decreases in abundance of Blautia, Roseburia, Coprococcus, Oscillibacter, as has been reported as decreased in IBD patients, ${ }^{15} 16$ as well as decreased abundance of Marvinbryantia, Acetatifactor and Pseudoflavonifractor (online supplementary figure S3). These bacterial alterations were observed 1 week after Phb1 deletion and decreases in abundance of Roseburia, Oscillibacter, Marvinbryantia and Acetatifactor and Shannon Diversity were sustained through 12 weeks after Phb1 deletion.
Ileal IECs exhibit mitochondrial dysfunction during deletion of Phb1

Since mitochondrial morphology is closely linked to function, mitochondria in epithelial cells of the ileum were visualised by transmission electron microscopy (TEM). Twelve weeks after induction of Phb1 deletion, ileal epithelial cells demonstrated loss of microvilli and increased vacuolation (online supplementary figure S4). $\mathrm{TUNEL}^{+}$staining in ileal crypts and villi of $P h b 1^{\text {i } \triangle I E C}$ mice suggest apoptosis and/or necrosis of the epithelium, confirmed by increased Cleaved caspase 3 expression (online supplementary figure S5A-C). A statistically significant proportion of the mitochondria of enterocytes, goblet cells, Paneth cells and crypt base columnar (CBC) stem cells of $P h b 1^{i \Delta I E C}$ mice were unhealthy (swollen, dissolution/delocalisation of cristae) or contained electrondense inclusion bodies as a reaction to injury ${ }^{17}$ (figure 2A,B). Mitochondrial dysfunction in $P h b 1^{i \triangle I E C}$ ileal IECs was also evident by decreased activity of ETC complexes I, II and IV (figure 2C) and the induction of the mitochondrial unfolded protein response (mtUPR; figure $2 \mathrm{D})$, which is triggered on

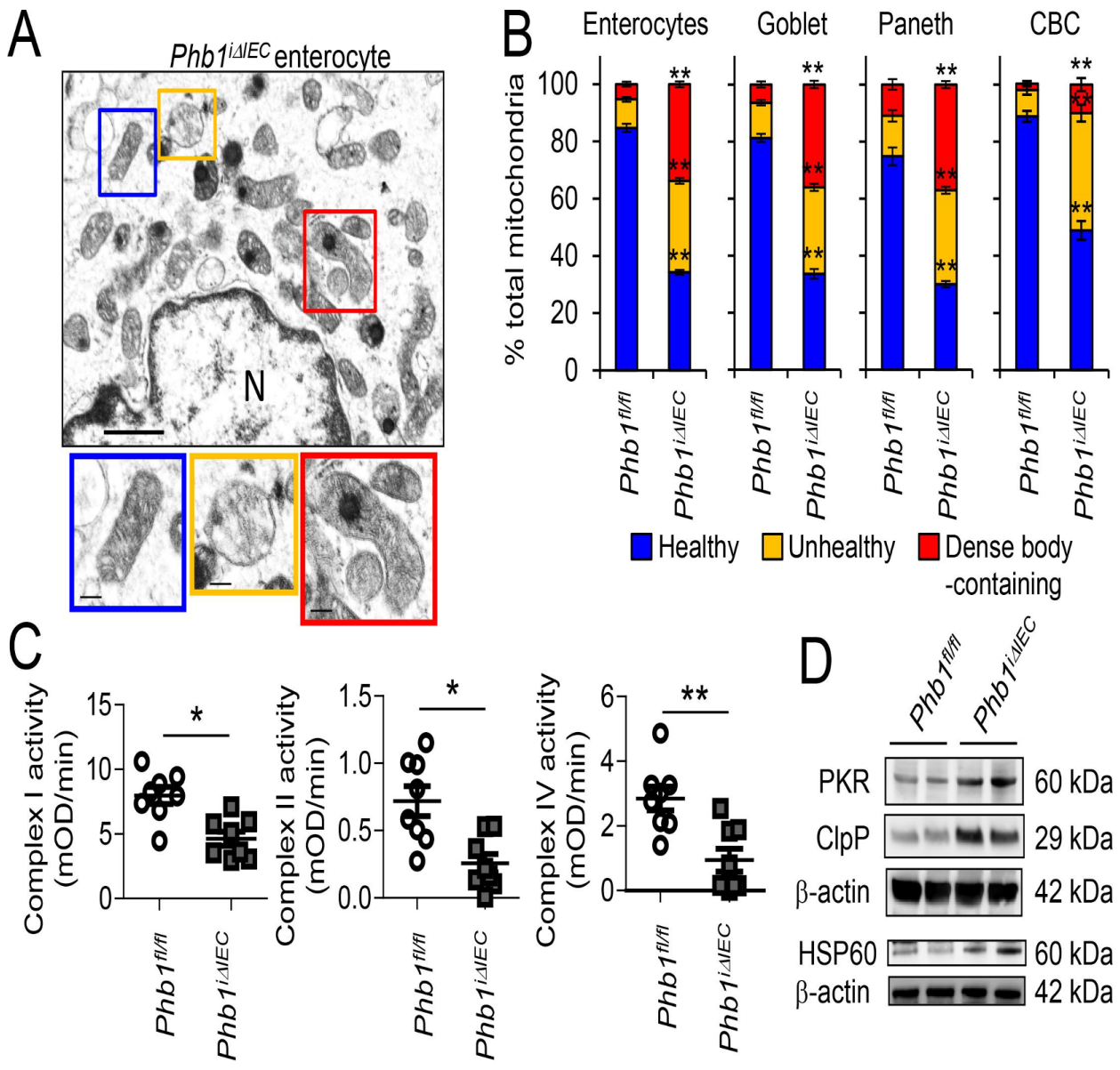

Figure $2 P h b 1^{\text {iLIEC }}$ ileal IECs exhibit mitochondrial dysfunction. Time point shown is 12 weeks after Phb1 deletion. (A) TEM of ileal enterocyte. Representative healthy (blue box), unhealthy (orange box), and dense inclusion body-containing (red box) mitochondria. Scale bars: $500 \mathrm{~nm}$. $\mathrm{N}$, nucleus. (B) \% healthy, unhealthy, and dense inclusion body-containing mitochondria visualised by TEM. $n=200$ enterocytes, 200 goblet cells, 50 Paneth cells, and 50 CBC cells with an average of 42 mitochondrial/cell. Enteroendocrine cells were too sparse to quantitate. (C) ETC complex activity in isolated ileal IECs. (D) Representative Western blots of mtUPR markers in isolated ileal IECs. Results are presented as pooled data means \pm SEM (B) or as individual data points \pm SEM $(C)$ of four mice per group (B) of eight mice per group (C, $D)$. ${ }^{*} P<0.05$, * $P<0.01$ by 1 -way ANOVA followed by Bonferroni's test (B) or by unpaired, 2-tailed Student's t-test (C). ANOVA, analysis of variance; $C B C$, crypt base columnar; ETC, electron transport chain; HSP, heat shock protein; IECs, intestinal epithelial cells; mUUPR, mitochondrial unfolded protein response; $P h b 1^{i \Delta I E C}$, intestinal epithelial cell deletion of Phb1; PKR, protein kinase R; SEM, standard error mean; TEM, transmission electron microscopy. 
Table 1 Proportion of $P h b 1^{\text {i } \Delta \mathrm{EEC}}$ mice that manifest mitochondrial dysfunction, abnormal Paneth and goblet cells, and histological inflammation

\begin{tabular}{|c|c|c|c|c|}
\hline $\begin{array}{l}\text { Week } \\
\text { after } \text { Phb1 } \\
\text { deletion }\end{array}$ & $\begin{array}{l}\text { Mice with } \\
\text { mitochondrial } \\
\text { dysfunction* N (\%) }\end{array}$ & $\begin{array}{l}\% \text { mice with } \\
\text { abnormal } \\
\text { Paneth cellst } \\
\text { n (\%) }\end{array}$ & $\begin{array}{l}\text { \% mice with } \\
\text { abnormal } \\
\mathrm{AB}^{+} \text {cells } ¥ n \\
(\%)\end{array}$ & $\begin{array}{l}\% \text { mice with } \\
\text { histological } \\
\text { inflammation } \\
\mathrm{n}(\%)\end{array}$ \\
\hline 1 & $12 / 12(100)$ & 4/12 (25) & 0/12 (0) & 0/12 (0) \\
\hline 3 & $12 / 12(100)$ & 7/12 (58) & $2 / 12(12)$ & $2 / 12(17)$ \\
\hline 6 & $\mathrm{~N} / \mathrm{D}$ & 10/14 (78) & 6/14 (43) & 6/14 (43) \\
\hline 12 & $15 / 15(100)$ & 13/15 (87) & 13/15 (87) & 13/15 (87) \\
\hline
\end{tabular}

* Defined as increased mtUPR, ultrastructural abnormalities in IECs by TEM.

†Defined as altered lysozyme staining, less abundant secretory granules, and $\mathrm{AB}^{+}$staining. ¥Defined as enlarged, more abundant $\mathrm{AB}^{+}$cells above the crypt base.

IEC, intestinal epithelial cell; mtPUR, mitochondrial unfolded protein response; N/D, not determined; Phb1 ${ }^{\text {i } \triangle \mathrm{EC}}$, intestinal epithelial cell deletion of Phb1; TEM, transmission electron microscopy.

accumulation of unfolded proteins within the mitochondrial matrix and is evident in epithelial cells from Crohn's disease and ulcerative colitis patients. ${ }^{8}$ These mitochondrial changes did not significantly alter ATP concentration in isolated ileal IECs (online supplementary figure S6A), as has been shown previously in other cells with Phb1 deficiency. ${ }^{18} 19$

Since mitochondrial dysfunction demonstrated in Phb1deficient ileal IECs could be secondary to inflammation, we next determined whether earlier time points after the induction of Phb1 deletion exhibited mitochondrial dysfunction. Mitochondrial ultrastructural abnormalities and mtUPR were induced in IECs as early as 1 week following Phb1 deletion and was sustained through 12 weeks (online supplementary figure S6B-E). Upregulation of Opa1, which is a master regulator of mitochondrial fusion and bioenergetics, but not other genes controlling mitochondrial function (Polg1, Polg2, Tfam or Pgc1), was evident early after Phb1 deletion in ileal IECs (online supplementary figure S6F). Additionally, endoplasmic reticulum (ER) stress and mitochondrial dysfunction can be interrelated during chronic inflammation with communication between the two organelles. ${ }^{20}$ Indeed, upregulation of ER UPR markers coincides with mitochondrial dysfunction in $P b b 1^{i \Delta I E C}$ ileal IECs (online supplementary figure S7A,B). Very few mice displayed histological inflammation of the ileum at early time points (1 or 3 weeks) following Phb1 deletion (table 1), suggesting that mitochondrial dysfunction precedes ileitis in this model.

Mitochondria are the primary source of ROS with $0.2 \%-$ $2.0 \%$ of oxygen consumed converted to superoxide by normal ETC activity. Mitochondrial dysfunction causes accumulation of mitochondrial-derived ROS (mtROS) due to blockade of forward electron flow through the ETC, subsequently causing more electrons to leak to oxygen. Oxidative damage to lipids and DNA is evident in the ileum of $P h b 1^{i \Delta I E C}$ mice as early as 1 week after Phb1 deletion (online supplementary figure S7C,D). Additionally, ROS-generating mitochondria have been shown to activate the $\mathrm{NLRP}_{3}$ inflammasome, which in turn leads to caspase-1 dependent secretion of proinflammatory cytokines IL-1 $\beta$ and IL-18. ${ }^{21} P h b 1^{i \Delta I E C}$ mice exhibit increased expression of active Caspase-1, IL-1 $\beta$ and IL-18 in ileum 1 week after Phb1 deletion without altered expression of other proinflammatory cytokines or chemokines commonly upregulated in intestinal inflammation at this early time point (online supplementary figure S8).
Phb $1^{\mathrm{i} \triangle \mathrm{IEC}}$ mice exhibit ileal Paneth cell abnormalities early after Phb1 deletion

During histological examination of H\&E-stained ileum sections, alterations in Paneth cells, such as smaller secretory granules, were obvious in $P h b 1^{i \Delta I E C}$ mice 12 weeks after $P h b 1$ deletion (figure 3A). Paneth cells contribute to gut homoeostasis by synthesising antimicrobial peptides and proteins such as lysozyme and defensins (also called cryptdins) and intestinal stem cell (ISC) niche factors. ${ }^{22}$ IHC staining demonstrated that lysozyme ${ }^{+}$ cells were expanded in number in $P h b 1^{i \Delta I E C}$ mice (figure 3B,C). Lysozyme is normally efficiently packaged into secretory granules in Paneth cells as demonstrated in $P b b 1^{f l / f l}$ mice (figure 3B). Ileal Paneth cells in $P h b 1^{i \Delta I E C}$ mice exhibited altered patterns of lysozyme allocation (as previously described by ${ }^{23}{ }^{24}$ ), with the majority showing diminished or diffuse lysozyme staining (figure 3B,D). Using these same criteria, 20\%-50\% of Crohn's disease patients have $\geq 20 \%$ abnormal Paneth cells (called Type I Paneth cell phenotype), which was associated with gut microbiota alterations and poor clinical outcomes such as early postoperative recurrence after resection. ${ }^{25-27}$ Paneth cell granules in $P h b 1^{i \Delta I E C}$ mice visualised by TEM were smaller and composed of an electron dense core and an enlarged electron-lucent peripheral halo compared with $P h b 1^{f l / f l}$ mice (figure $3 \mathrm{E}$ ). Previous studies have identified this electron-lucent halo in murine Paneth cells as predominantly containing Mucin $2 .^{28} \mathrm{Phb} 1^{i \Delta I E C}$ mice exhibited decreased mRNA expression of antimicrobials produced by Paneth cells such as RegIII $\gamma$, Cryptdin3, Cryptdin 5 and Ang4 (online supplementary figure S9A), suggesting loss of Paneth cell function vs simply degranulation of Paneth cell enzymes on a sustained basis.

Goblet-like cells containing dense core mucin granules, or a combination of mucin granules and abnormal Paneth cell granules, were observed in the crypt base of $P h b 1^{i \Delta I E C}$ mice by TEM (figure 3E). Alcian blue (AB)-periodic acid schiff staining confirmed an increase in the number of $\mathrm{AB}^{+}$cells in the crypt base during Phb1 deletion (figure 4A,B). Colocalisation of MUC2 (goblet cell marker) and lysozyme (Paneth cell marker) staining in the $P h b 1^{i \Delta I E C}$ crypt base, evident in areas with and without inflammation, suggest these cells are 'intermediate' goblet/Paneth cells (figure 4C). These intermediate cells have been proposed to be Paneth cells undergoing transformation to goblet cells, goblet cells in the process of being converted to Paneth cells, or a precursor of both lineages. This altered differentiation programme in $P h b 1^{i \Delta I E C}$ crypts was accompanied by increased $\mathrm{TUNEL}^{+}$staining and cell proliferation (online supplementary figure S5), suggesting increased turnover of the intestinal epithelium.

In addition to the appearance of intermediate cells in the ileal crypts of $P h b 1^{i \Delta I E C}$ mice, $\mathrm{AB}^{+}$cells above the crypt base were increased in number and size with increased cytoplasmic mucin/cell (figure 4B-E). Examination of ileum at earlier time points after the induction of $P h b 1$ deletion demonstrated that crypt intermediate cells are evident before abnormal villus $\mathrm{AB}^{+}$ cells (table 1 and online supplementary figure S9B,C). As early as 1 week after Phb1 deletion, mRNA expression of goblet cell genes $M u c 2$ and $M u c 4$ are increased with a concomitant increase in Klf4 and Elf3 (online supplementary figure S9A), which are transcription factors involved in goblet cell differentiation. $P h b 1{ }^{\text {iSIEC }}$ mice exhibited decreased mRNA expression of Hes 1 and increased Math1 (online supplementary figure S9A), a situation that has been shown to promote secretory cell differentiation. ${ }^{29}$ Sox9, which controls, at least in part, Paneth cell differentiation, and Lgr5, the intestinal CBC stem cell marker, 


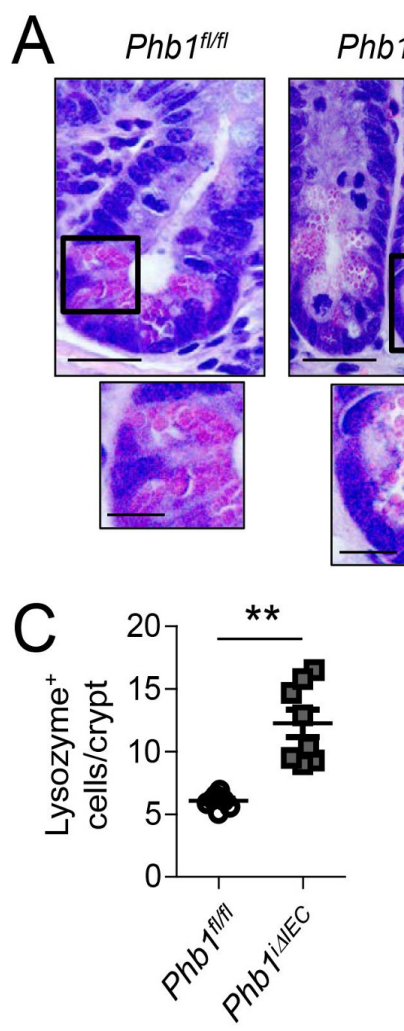

Phb1 $1^{\text {IIIEC }}$

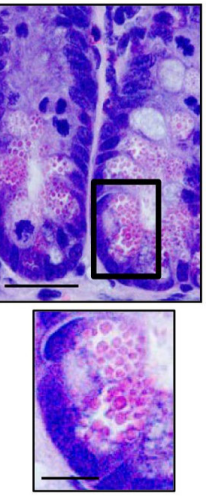

B
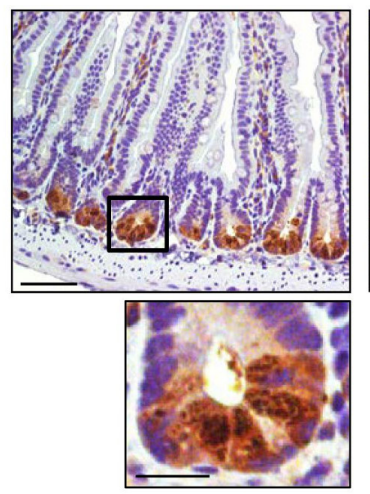

Phb1 $1^{\text {IIIEC }}$

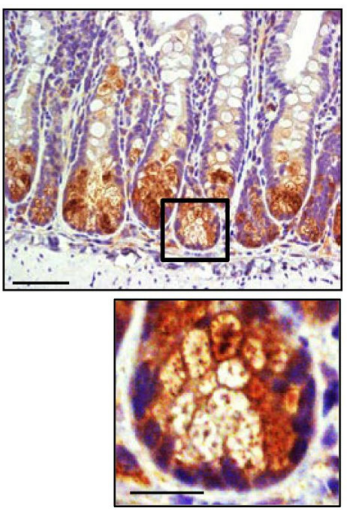

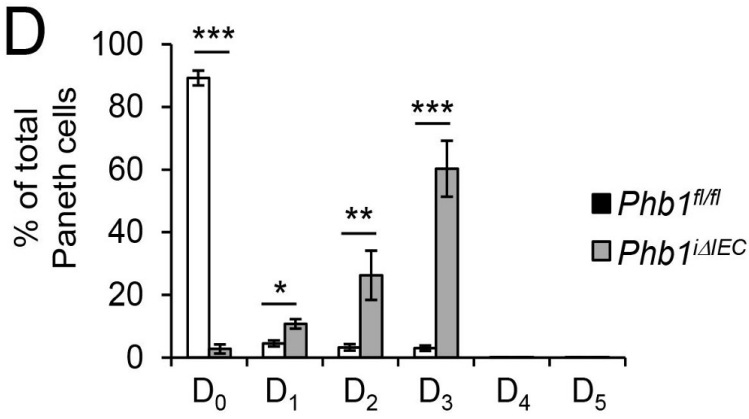

$E$
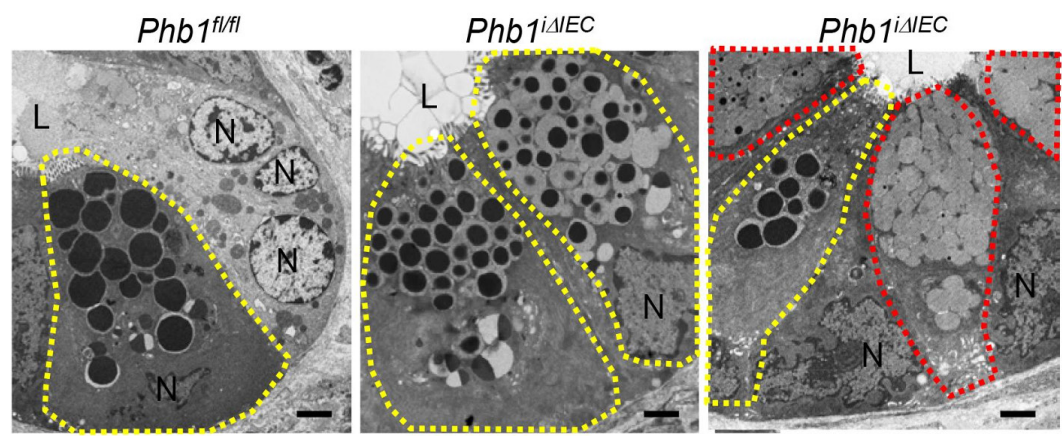

Figure 3 Phb1 ${ }^{\triangle I E C}$ mice exhibit ileal Paneth cell abnormalities. Time point shown is 12 weeks afetr Phb1 deletion. (A) H\&E-stained sections showing Paneth cells. Scale bars: $50 \mu \mathrm{m}$, boxed pullout: $20 \mu \mathrm{m}$. (B) Lysozyme IHC staining. Scale bars: $250 \mu \mathrm{m}$, boxed pullouts: $50 \mu \mathrm{m}$ (C) The number of lysozyme+ cells across 50 crypts per mouse. (D) \% of Paneth cells displaying each pattern of lysozyme expression. D0, normal; D1, disordered; D2, diminished; D3, diffuse; D4, excluded; D5, enlarged. 500 cells quantitated each mouse. (E) TEM of crypt base. Paneth cells, yellow outline; goblet-like cells, red outline. N, nucleus; L, lumen. Scale bars: $2 \mu \mathrm{m}$. Results are presented as individual data points \pm SEM (C) or as pooled data means \pm SEM (D) of 8 mice per group. ${ }^{* *} \mathrm{P}<0.01,{ }^{* *} \mathrm{p}<0.001$ by unpaired, 2 -tailed Student's $\mathrm{t}$-test. (B) Or by 1-way ANOVA followed by Bonferroni's test (D). ANOVA, analysis of variance; $P h b 1^{\Delta I E C}$, intestinal epithelial cell deletion of $P h b 1$.

were not altered in $P h b 1^{i \Delta I E C}$ mice (online supplementary figure S9A). FABP6 immunostaining suggests that enterocyte numbers are decreased by 12 weeks after $P h b 1$ deletion but not as early as 1 week, while enteroendocrine cells (marked by chromogranin $\mathrm{A}^{+}$expression) were unaffected in $P h b 1^{i \Delta I E C}$ mice (online supplementary figure S10).

To determine the sequence of pathological events driving ileal inflammation in $P h b 1^{i \Delta I E C}$ mice, the proportion of mice that manifest ileitis, Paneth cell or villus $\mathrm{AB}^{+}$cell abnormalities, or mitochondrial dysfunction at $1,3,6$ or 12 weeks after the induction of Phb1 deletion were quantitated. Mitochondrial dysfunction was evident in all mice at 1 week, Paneth cell abnormalities in the majority of mice beginning at 3 weeks, followed by villus $\mathrm{AB}^{+}$cell abnormalities and spontaneous ileitis, which developed in the majority of mice after 6 weeks (table 1). Collectively, these results demonstrate that the loss of Phb1 causes mitochondrial dysfunction and subsequent Paneth cell defects prior to the onset of ileitis.

\section{Mito-Tempo ameliorates mitochondrial dysfunction, Paneth cell defects and ileitis during loss of $P h b 1$}

To determine whether a mitochondrial-targeted antioxidant has therapeutic potential in Paneth cells, the dysfunction of which plays a role in the pathogenesis of Crohn's disease, ${ }^{22}$ a subset of mice were treated daily for 3 weeks with Mito-Tempo concurrent with tamoxifen injections to induce Phb1 deletion. Mito-Tempo is a mitochondrial-targeted superoxide dismutase 2 mimetic shown to have antioxidant properties. ${ }^{30}$ Mito-Tempo ameliorated mitochondrial ultrastructural abnormalities and mtUPR and ER UPR responses in Phb1 $1^{\text {iSIEC }}$ ileal IECs (figure $5 \mathrm{~A}-\mathrm{C}$ ). Additionally, Mito-Tempo restored lysozyme staining and 

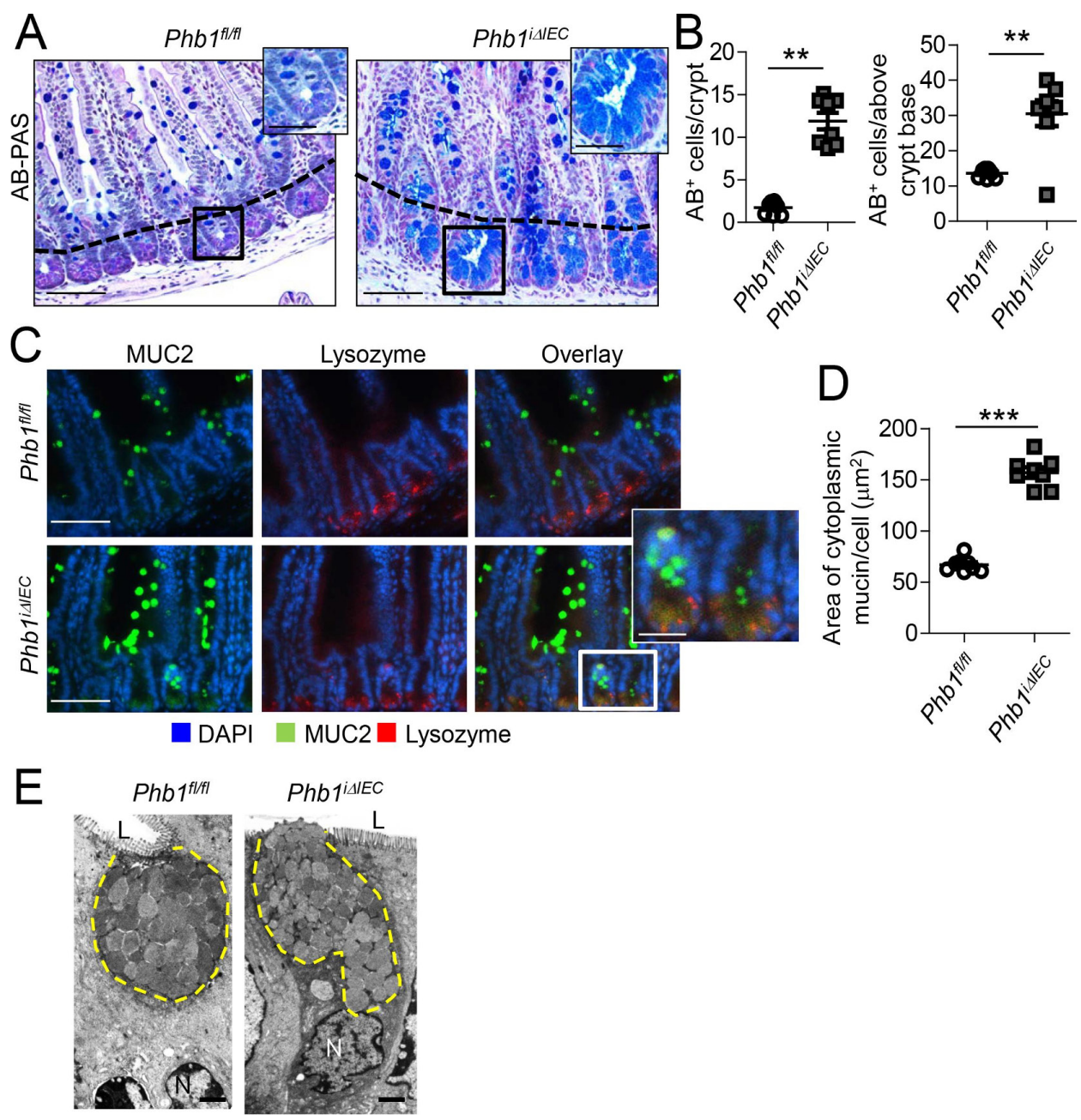

Figure 4 lleal Paneth cells resemble goblet/Paneth intermediate cells and goblet cell number and size are increased in $P h b 1^{\text {i } \Delta I E C}$ mice. Time point shown is 12 weeks after Phb1 deletion (A) AB-PAS-stained sections. Dashed line denotes crypt base. Scale bars: $250 \mu \mathrm{m}$, boxed pullouts: $50 \mu \mathrm{m}$. (B) The number of $A B^{+}$cells in the crypt base (below dashed line in A) or above the crypt base across 50 crypts per mouse. (C) MUC2 (goblet cell marker) and Lysozyme (Paneth cell marker) immunofluorescene staining. Scale bars: $250 \mu \mathrm{m}$, boxed pullout showing co-localisation: $75 \mu \mathrm{m}$. (D) Quantitation of average mucin area/goblet cell above the crypt base. 250 cells quantitated each mouse. (E) TEM of villus goblet cells. Mucin granules, yellow outline. Scale bars: $1 \mu \mathrm{m}$. Results are presented as individual data points \pm SEM of 8 mice per group. ${ }^{*} \mathrm{P}<0.01,{ }^{* * *} \mathrm{p}<0.001$ by unpaired, 2 -tailed student's $\mathrm{t}$ test. AB-PAS, alcian blue-periodic acid schiff; L, lumen; MUC2, mucin2; N, nucleus; Phb1 ${ }^{\text {i IEC }}$, intestinal epithelial cell deletion of Phb1; SEM, standard error mean; TEM, transmission electron microscopy.

Paneth cell antimicrobial expression such as RegIII $\gamma$, Cryptdin3 and Cryptdin 5 in Phb1 $1^{\text {isIEC }}$ mice (figure $5 \mathrm{D}, \mathrm{E}$ ). $\mathrm{AB}^{+}$crypt cells and expression of $M u c 2$ and Muc4 in $P h b 1^{i \Delta I E C}$ mice treated with Mito-Tempo was similar to $P h b 1^{f l / f l}$ mice (figure $5 \mathrm{D}, \mathrm{E}$ ), suggesting that Mito-Tempo prevented differentiation changes favouring intermediate cells during Phb1 deletion. Mito-Tempo also prevented the upregulation of $I l-1 \beta$ and $I l-18$ in the ileum that was induced during Phb1 deletion (figure 5F). We continued administration of Mito-Tempo for an additional 9 weeks to assess severity of ileitis (figure 5G). Only 20\% (2/10 mice) of Pbb1 $1^{i \Delta I E C}$ mice treated with Mito-Tempo through 12 weeks exhibited histological evidence of inflammation in the ileum, compared with $80 \%$ (8/10 mice) of $P h b 1^{i \Delta I E C}$ mice treated with vehicle.

Since Tempo not targeted to the mitochondria has been shown to affect microbiota, ${ }^{31}$ we administered Mito-Tempo in vitro using ileal enteroids to eliminate microbiota as a confounding factor and to examine epithelial cell-intrinsic responses. Enteroids derived from $P h b 1^{i \Delta I E C}$ mice formed fewer crypt buds and exhibited significant death during the 7-day culture period compared with enteroids derived from $P h b 1^{f l f l}$ mice (online supplementary figure S11A-C). Phb1 ${ }^{\text {iSIEC }}$ enteroids also displayed activation of the mtUPR and ER UPR, increased production of mitochondrialderived superoxide and loss of expression of Paneth cell antimicrobials RegIII $\gamma$, Cryptdin3, Cryptdin5 and Ang4 (online supplementary figure S11F,G). Mito-Tempo decreased $P h b 1^{\text {i } \Delta I E C}$ enteroid death, mitochondrial-derived superoxide production, mtUPR and ER UPR activation and restored expression of Paneth cell antimicrobials to that of $P h b 1^{f l / f l}$ enteroids (online supplementary figure S11E-G). Mito-Tempo had no effect on crypt budding (online supplementary figure S11D). These results suggest that mtROS contributes to Paneth cell defects and loss of viability of the ISC niche during IEC Phb1 deficiency.

\section{Mice with Paneth cell-specific deletion of Phb1 develop spontaneous ileitis}

To delineate the role of mitochondrial dysfunction specifically in Paneth cells and its effect on ileitis, we generated two mouse lines with Paneth cell-specific deletion by crossing $P h b 1^{f l / f l}$ mice to Defa6-Cre mice $\left(P h b 1^{\text {Defa6 } \triangle P C}\right)$ and to Mist1-CreER ${ }^{T 2}$ mice 

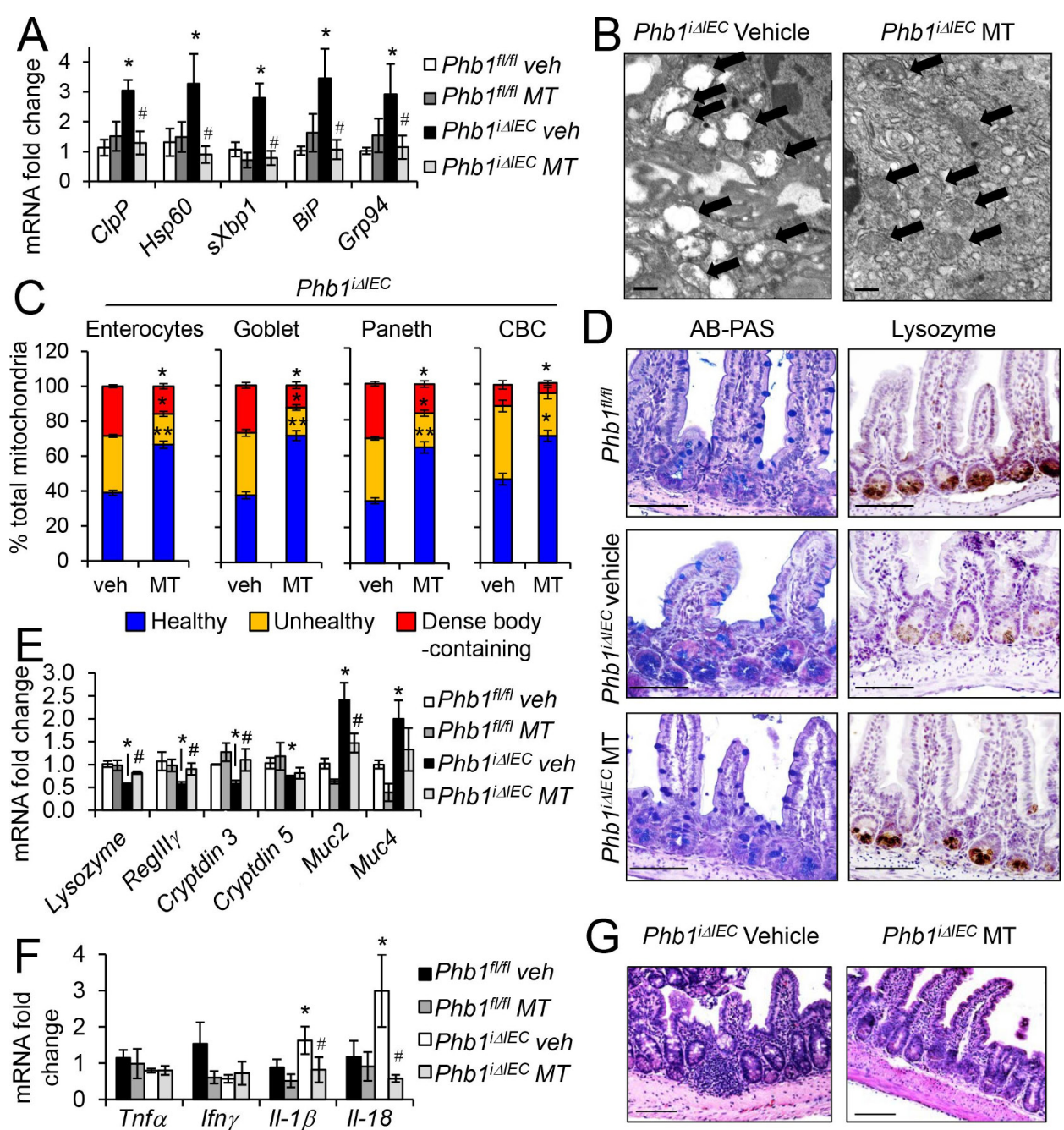

Figure 5 Mito-Tempo (MT) ameliorates mitochondrial dysfunction, Paneth cells defects, and ileitis in Phb1 ${ }^{\text {iLIEC }}$ ileum. (A) mRNA expression of mtUPR (ClpP, Hsp60) and ER UPR (sXbp1, BiP, Grp94) markers in isolated ileal IECs measured by qPCR. (B) TEM of ileal enterocytes. Arrows indicate mitochondria. Scale bars: $500 \mathrm{~nm}$. (C) \% healthy, unhealthy (swollen, dissolution of cristae), and dense inclusion body-containing mitochondria visualized by TEM. $n=200$ enterocytes, 200 goblet cells, 50 Paneth cells, and 50 CBC cells with an average of 53 mitochondrial/cell. (D) AB-PAS and Lysozyme immunohistochemistry staining. Scale bars: $250 \mu \mathrm{m}$. mRNA expression in isolated ileal IECs (E) or whole ileum (F) measured by qPCR. (G) H\&E-stained sections showing ileum histology at 12 weeks. Scale bars: $250 \mu \mathrm{m}$. Results are presented as pooled data means \pm SEM of 6 mice per group $(A, E, F)$ or 4 mice per group (C). ${ }^{*} P<0.05,{ }^{* *} p<0.01$ vs $P h b 1^{f / f / t}$ veh, ${ }^{\#} p<0.05$ vs $P h b 1^{i \Delta I E C}$ veh by 1 -way ANOVA followed by Bonferroni's test. AB-PAS, alcian blue-periodic acid schiff; ANOVA, analysis of variance; CBC, crypt base columnar; ER, endoplasmic reticulum; IECs, intestinal epithelial cells; IFN- $\gamma$, interferon- $\gamma$; IL-18, interleukin-18; mUUPR, mitochondrial unfolded protein response; $P h b 1^{\text {iLIEC }}$, intestinal epithelial cell deletion of $P h b 1$; TEM, transmission electron microscopy; TNF $\alpha$, tumour necrosis factor $\alpha$.

$\left(P h b 1^{i M i s t 1 \Delta P C}\right)$. MIST1 (BHLHA15) is a critical transcription factor expressed in mature exocrine secretory cells like Paneth cells. ${ }^{32}$ Robust expression of PHB1 was demonstrated in Phb1 ${ }^{f l l}$ $f l$ mice and confirmed to be deficient in $P b b 1^{\text {Defa6 } \triangle P C}$ and $P h b 1^{i-}$ Mist $1 \triangle P C$ mice (online supplementary figures S12A and S14A). $P h b 1^{\text {Defa. } \triangle P C}$ and Phb1 $1^{\text {iMist } 1 \Delta P C}$ mice developed spontaneous, discontinuous ileitis with similar characteristics to that seen in $\mathrm{Phb}^{i \triangle I E C}$ mice such as infiltration of $\mathrm{CD}^{+} \mathrm{T}$ cells, $\mathrm{CD} 11 \mathrm{~b}^{+} /$ CD $11 \mathrm{c}^{+}$dendritic cells and $\mathrm{F} 4 / 80^{+}$macrophages, crypt elongation, villus blunting and thickening of the muscularis layers (figure 6A,B, online supplementary figures S12B, S14B-D). Inflammation was restricted to the ileum (online supplementary figures S12C and S14C). Despite these similarities, the penetrance of ileitis across $P h b 1^{\text {Defa. } \triangle P C}$ and $P h b 1^{\text {iMist } 1 \Delta P C}$ was lower than in $P b b 1^{i \Delta I E C}$ mice (table 1 and online supplementary table S1). Much like $P h b 1^{i \Delta I E C}$ mice, inflammation in $P h b 1^{\text {Defa6 } \triangle P C}$ and $P h b 1^{i \text { ist } 1 \triangle P C}$ mice was associated with less body weight gain, enlarged spleens, and an early increase in $I l-1 \beta$ and $I l-18$ expression followed by later increased $T n f \alpha$ and $I f n \gamma$ and decreased $I l-10$ (figure 6C, online supplementary figures S12D, S12E, S14E-F). Paneth cell abnormalities were evident as early as 1 week after the induction of $P h b 1$ deletion in $P h b 1^{\text {iMist } 1 \Delta P C}$ mice and by 8 weeks of age in $P h b 1^{\text {Defa6 } \triangle P C}$, with altered lysozyme staining allocation pattern and increased $\mathrm{AB}^{+}$staining (figure $6 \mathrm{E}-\mathrm{F}$, online supplementary figures S13A-C and S15A-F). Unlike Phb1 $1^{i \Delta I E C}$ mice, the number of lysozyme ${ }^{+}$cells in $P h b 1^{\triangle P C}$ crypts was decreased compared with $P h b 1^{\text {fllfl }}$ mice (figure 6D and online supplementary figure S15C). Goblet cells above the crypt base in $P h b 1^{\text {Defa. } \triangle P C}$ and $P h b 1^{i \text { Mist } 1 \Delta P C}$ mice appeared similar to $P b b 1^{f l f l}$ mice throughout all time points studied (figure 6F, online supplementary figures S13D, S15F). Altered expression of Paneth cell antimicrobials, Muc2 and Muc4, and Hes1 and Math1 in $P h b 1^{\text {Defa. } \triangle \triangle P C}$ mice matched the expression pattern displayed by $P h b 1^{i \Delta I E C}$ mice (online supplementary figure S13E). 


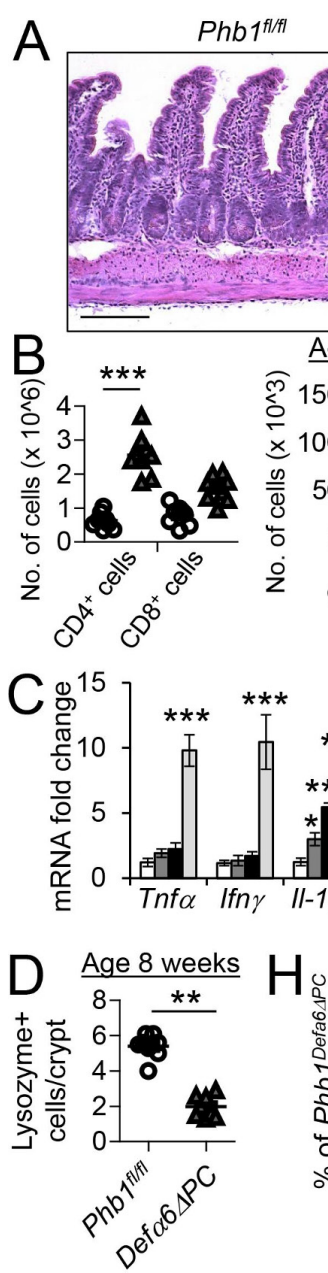

Age 20 weeks $P h b 1$ Def $\alpha 61 P C$

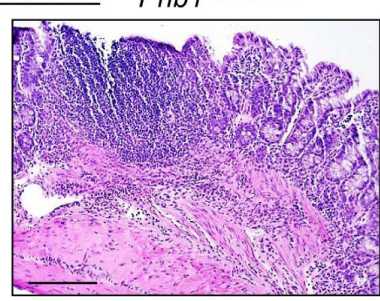

Age 20 weeks

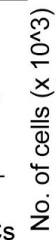

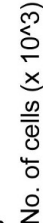

¿̊ํㄴ 150 **

$\times 100-$

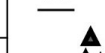

$\Delta$

0

$\begin{array}{cl}{\mathrm{CD} 11 \mathrm{~b}^{+} /}_{\mathrm{CD} 11 \mathrm{c}^{+} \mathrm{DCs}} \stackrel{\mathrm{C}}{\mathrm{CD} 11 \mathrm{~b}^{+} /} \\ & \mathrm{CD} 11 \mathrm{c}^{-} / \\ & \mathrm{F} 4 / 80^{+}\end{array}$

$\begin{array}{cl}\mathrm{CD}_{11 \mathrm{~b}^{+} /} \stackrel{\mathrm{C}}{\mathrm{CD} 11 \mathrm{~b}^{+} /} \\ \mathrm{CD} 11 \mathrm{c}^{+} \mathrm{DCs} & \mathrm{CD} 11 \mathrm{c}^{-1} \\ & \mathrm{~F} 4 / 80^{+}\end{array}$

$\begin{array}{cl}\mathrm{CD}_{\mathrm{C} 11 \mathrm{~b}^{+} /} \text {i } & \mathrm{CD} 11 \mathrm{~b}^{+} / \\ \mathrm{CD} 11 \mathrm{c}^{+} \mathrm{DCs} & \mathrm{CD} 11 \mathrm{c}^{-} / \\ & \mathrm{F} 4 / 80^{+}\end{array}$

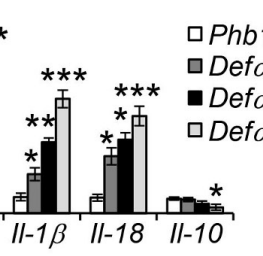

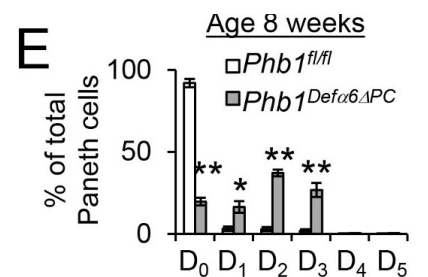

$F \quad$ Age 8 weeks

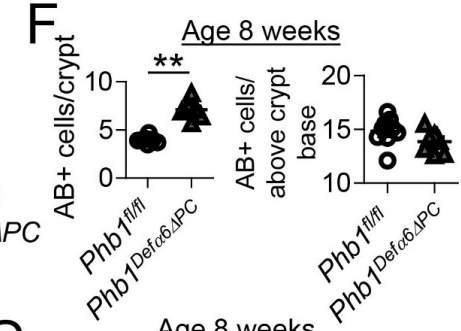

Figure 6 Phb1 ${ }^{\text {Defa6 } \Delta C}$ mice develop mitochondrial dysfunction, Paneth cell defects, and spontaneous ileitis. (A) H\&E-stained ileum sections at 20 weeks of age. Scale bars: $250 \mu \mathrm{m}$. (B) Absolute number of ileal LP immune cells calculated of total ileal LP cells. (C) mRNA expression in ileum measured by qPCR. (D) The number of Lysozyme ${ }^{+}$cells across 50 crypts per mouse. (E) \% of Paneth cells displaying each pattern of Lysozyme expression. 50 cells quantitated each mouse. (F) The number of $A B+$ cells in the crypt base or above the crypt base across 50 crypts per mouse. (G) TEM of $P h b 1^{\text {Defa.6 } \triangle P C}$ ileum crypt base. Paneth cells, yellow outline; goblet-like cells, red outline; Paneth cell with vesiculated ER, green outline. Scale bars: $1 \mu \mathrm{m}$. Box denotes area of higher magnification showing unhealthy mitochondria. $(\mathrm{H}) \%$ of Paneth cells displaying vesiculated ER. Results are presented as individual data points $\pm \operatorname{SEM}(B, D, F)$ or as pooled data means \pm SEM $(C, E)$ of 9 mice per group. ${ }^{*} P<0.05,{ }^{*} p<0.01,{ }^{* * *} p<0.001$ vs $\mathrm{PHB1}^{\mathrm{fl} / \mathrm{fl}}$ by unpaired, 2-tailed Student's t test (B, D, F) or by 1-way ANOVA followed by Bonferroni's test (C, E). ANOVA, analysis of variance; ER, endoplasmic reticulum; IL-10, interleukin-10; IFN- $\gamma$, interferon- $\gamma$; L, lumen; N, nucleus; TEM, transmission electron microscopy; TNF $\alpha$, tumour necrosis factor $\alpha$.

TEM analysis 1 week after $P h b 1$ deletion in $P h b 1^{\text {Mist } 1 \Delta P C}$ mice and at 8 weeks of age in $P h b 1^{\text {Defa6 } \triangle P C}$ mice demonstrated similar mitochondrial ultrastructural changes in Paneth cells, but not other IECs, as those demonstrated in $P h b 1^{\text {i } \triangle I E C}$ mice (figure $6 \mathrm{G}$, online supplementary figures S13F, S15G, and S15H). Enteroids derived from $P h b 1^{\text {Defa6 } \triangle P C}$ or $P h b 1^{\text {iMist } 1 \Delta P C}$ mice exhibited decreased crypt budding similar to $P h b 1^{i \Delta I E C}$ enteroids, but less severe enteroid death and mitochondrial superoxide production compared with $P h b 1^{i \Delta I E C}$ enteroids that was further decreased by Mito-Tempo treatment (online supplementary figure S11B-

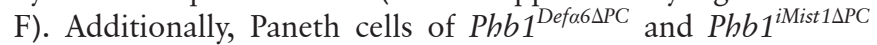
mice exhibited secretory granule alterations and the appearance of goblet/Paneth intermediate cells similar to $P h b 1^{i \Delta I E C}$ mice (figure 6G and online supplementary figure $\mathrm{S} 15 \mathrm{H}$ ). Interestingly, a significant proportion of $P h b 1^{\text {Defa.6 } \Delta P C}$ and $P h b 1^{\text {iMist } 1 \Delta P C}$ Paneth cells manifested vesiculated ER in addition to damaged mitochondria, suggesting severe ER stress which was corroborated by elevated ER UPR markers (figure 6G,H, online supplementary figures S13G, S15H, and S15I). A similar progression to ileitis was evident in $P h b 1^{\text {Defa.6APC }}$ and $P h b 1^{i \text { Mist } 1 \Delta P C}$ mice as was noted in $P h b 1^{i \Delta I E C}$ mice with initial mitochondrial dysfunction, followed by Paneth cell defects and subsequent ileal inflammation (table 1 and online supplementary table S1). Collectively, these results suggest that mitochondrial dysfunction due to Phb1 deletion in Paneth cells is sufficient to drive ileitis.

\section{DISCUSSION}

Mitochondrial dysfunction is central to many chronic diseases, including arthritis, neurodegeneration, cardiovascular disease and cancer. Previous studies suggest a link between mitochondrial dysfunction and Crohn's disease. The paediatric RISK stratification study using RNA-sequencing analysis on Crohn's disease mucosal biopsies demonstrated that of patients who were at risk of stricturing, those who exhibited an enriched mitochondrial function gene signature remained complication free 
through 36-month follow-up. ${ }^{33}$ In a proteome study of paediatric Crohn's disease patients, impaired mitochondrial function was implicated and correlated with increased disease severity. ${ }^{34}$ It was recently demonstrated that mtDNA is released into the serum in IBD patients and acts as a proinflammatory signalling molecule. ${ }^{7}$ Deletion of Irgm, Slc22A5, Pgc1 $\alpha$ or Mdr1, genes that serve roles in regulating mitochondrial health, cause spontaneous colitis or increase susceptibility to experimental colitis. ${ }^{45}$ Well-characterised mouse models of spontaneous ileitis such as SAMP1/Yit or TNF ${ }^{\triangle A R E}$ mice have not been examined for IEC mitochondrial dysfunction, but ileal histological alterations of $P h b 1^{i \triangle I E C}$ or $P h b^{\triangle P C}$ mice were reminiscent to that of SAMP1/ Yit mice. ${ }^{35}$ Expression of PHB1 is decreased in mucosal biopsies from IBD-afflicted patients and in mouse models of colitis, ${ }^{911}$ but the mechanism leading to decreased PHB1 expression in human IBD is unknown. IBD GWAS studies have not identified genetic mutation of PHB1. Genetic polymorphisms of $P H B 1$ have been associated with gastric, breast, ovarian and skin cancers with some studies implicating regulation at the $3^{\prime} \mathrm{UTR},{ }^{36}$ however, this has not been identified in IBD. Further studies are necessary to elucidate the mechanism of PHB1 deficiency during IBD.

Our results identify Paneth cells as highly susceptible to mitochondrial dysfunction driven by loss of Phb1 and central to the pathogenesis of ileitis. A total of 70\%-80\% of Crohn's disease patients have inflammation involving the ileum, with or without colonic involvement. Mitochondrial dysfunction in IECs during Phb1 deletion was evidenced by mitochondrial ultrastructural abnormalities, decreased activity of ETC complexes, increased mtROS and oxidative damage to lipids and DNA. These mitochondrial changes did not significantly alter ATP concentration in isolated ileal IECs, suggesting that IECs as a population have adequate energy production. Future studies will access individual IEC types like Paneth cells for ATP production. Mitochondrial health may be especially important in intestinal secretory cells (Paneth, goblet and enteroendocrine cells) which are mitochondria-rich to sustain energy-expending secretory functions. Additionally, mitochondrial dysfunction is likely to be especially deleterious in terminally differentiated long-lived cells, such as Paneth cells, in which damaged organelles are not diluted by cell replication. ${ }^{22}$ Type I Paneth cell phenotype, characterised by $\geq 20 \%$ abnormal Paneth cells, defined by lysozyme granule staining characteristics (disordered, diminished, diffuse, enlarged or excluded) using mucosal biopsy samples, ${ }^{27}$ occurs in approximately $20 \%$ of adult ileal Crohn's disease patients and is independent of active inflammation. ${ }^{2526}$ Crohn's diseaseassociated ATG16L1 T300A and NOD2 risk alleles were shown to correlate with type I Paneth cell phenotype. ${ }^{23} 27$ ATG16L1 and NOD2 play important roles in autophagy, an evolutionarily conserved catabolic pathway that removes cytoplasmic components, including damaged organelles, through lysosomal degradation. The autophagy pathway is crucial to suppress ileitis during Xbp1 deletion in Paneth cells. ${ }^{37}$ It is likely that mitophagy (autophagy of mitochondria) plays an important role in intestinal homoeostasis, but this has yet to be demonstrated in patients with IBD. Interestingly, patients with Crohn's disease with type I Paneth cell defects exhibited decreased expression of oxidative phosphorylation genes, suggesting this subset of patients may have altered mucosal mitochondrial function, but this was not further elucidated. ${ }^{26}$ Our current results provide a mechanistic link between loss of PHB1, mitochondrial dysfunction and Paneth cell defects, which are three characteristics demonstrated in patients with Crohn's disease. Future studies will elucidate whether type I Paneth cell patients exhibit mitochondrial dysfunction, altered mitophagy or altered PHB1 expression.
mtROS are well-established primary downstream signalling molecules and, if excessive, mtROS can lead to cellular damage. Treatment of $P h b 1^{i \Delta I E C}$ mice with the mitochondrial-targeted antioxidant Mito-Tempo ameliorated Paneth cell defects and ileitis during loss of Phb1. Mito-Tempo also prevented the upregulation of $I l-1 \beta$ and $I l-18$ in the ileum of $P h b 1^{i \Delta I E C}$ mice, suggesting that mtROS contributes to early increased secretion of these cytokines. Our results indicate that epithelial mitochondrial dysfunction evident 1 week after Phb1 deletion concomitantly occurs with enhanced secretion of IL-1 $\beta$ and IL-18. Future studies will determine whether the mtROS signalling via the $\mathrm{NLRP}_{3}$ inflammasome is involved in enhanced secretion of IL-1 $\beta$ and IL-18 in this model and the cellular source of these cytokines. Additionally, in Phb1-deficient enteroids, MitoTempo increased viability, decreased mtROS, decreased mtUPR and ER UPR activation, and restored expression of Paneth cell antimicrobials to that of $P h b 1^{f l / f l}$ enteroids, suggesting epithelial cell-intrinsic responses to Mito-Tempo. These results demonstrate that mtROS contributes to Paneth cell defects and loss of viability of the ISC niche during IEC Phb1 deficiency and present a druggable pathway for therapeutic targeting.

Mitochondrial function is a crucial modulator of stem cell fate in relatively quiescent stem cell populations, including haematopoietic stem cells and neural stem cells, as well as more active ISCs requiring more bioenergetics activity due to frequent turnover of the intestinal epithelium. ${ }^{38} \mathrm{Phb} 1^{\text {iIIEC }}$ mice demonstrated Paneth/goblet intermediate cells early after Phb1 deletion prior to signs of histological inflammation, followed by later increased number and size of goblet cells and decreased enterocytes. This altered differentiation programme in $P h b 1^{i \Delta I E C}$ crypts was accompanied by increased crypt cell proliferation and apoptosis in crypts and villi, likely as a consequence of tissue repair induction. Goblet and Paneth cells differentiate from a common secretory cell lineage progenitor that is distinct from the enterocyte cell lineage progenitor. ${ }^{29}$ Differentiation towards the secretory cell lineage is mediated by at least two transcription factors, Hes1 and Math1, which are altered in $P h b 1^{i \Delta I E C}$ mice in a manner shown to favour secretory cell differentiation. Additionally, Klf4 is increased in $P h b 1^{\text {isIEC }}$ ileum and has been shown to be required for goblet cell-differentiation. ${ }^{39}$ Intermediate cells in $P h b 1^{i \Delta I E C}$ mice could originate from changes in the Paneth cell itself to promote transformation to a goblet cell, goblet cells being converted to Paneth cells, or stem cell responses driving altered lineage differentiation. It was previously shown that ISC mitochondrial dysfunction and decreased ability to produce ATP results in altered ISC self-renewal and proliferation. ${ }^{38}$ We speculate that altered Paneth/goblet cell differentiation in ileum of $P h b 1^{\text {i IIEC }}$ mice could be due to (1) PHB1 directly regulating the Notch-1 (upstream of Hes1/Math1) and/or Klf4 pathways, (2) modulation of Notch-1 and/or Klf4 by redox-dependent signalling or mitochondrial dysfunction subsequent to PHB1 deletion and/or (3) a response to inflammation, however, this seems unlikely since altered secretory allocation was demonstrated preceding histological signs of inflammation. Additionally, IL-18 plays an important role in goblet cell differentiation ${ }^{40} 41$ and future studies will assess whether the Paneth/goblet intermediate cells observed in $P h b 1^{\text {iSIEC }}$ mice are driven by IL-18 to prevent goblet cell maturation.

Paneth cell-specific deletion of Phb1 induced a similar progression to ileitis as was demonstrated in $P h b 1^{i \Delta I E C}$ mice with initial mitochondrial dysfunction and Paneth cell defects. At early time points, mitochondrial dysfunction was evident in only Paneth cells in $P h b 1^{\triangle P C}$ mice, and not other IECs, confirming the importance of a healthy mitochondrial pool in Paneth cells 
in maintaining intestinal homoeostasis. Penetrance of inflammation across $P h b 1^{\triangle P C}$ mice was less than $P h b 1^{i \Delta I E C}$ mice, suggesting mitochondrial dysfunction throughout the intestinal epithelium, as in $P h b 1^{i \Delta I E C}$ mice, accelerates the progression to inflammation. Indeed, enteroids derived from $P h b 1^{i \Delta I E C}$ mice exhibited more severe death and mitochondrial superoxide production compared with $P h b 1^{\text {Defa } 6 \Delta P C}$ or $P h b 1^{i \text { ists } 1 \triangle P C}$ enteroids. Unlike in $P h b 1^{\text {iLIEC }}$ mice, $\mathrm{AB}^{+}$cells above the crypt base in Phb1 $1^{\text {Defa } 6 \triangle P C}$ and $P h b 1^{i \text { Mist } 1 \triangle P C}$ mice appeared normal throughout all time points examined with no alteration of Klf4 or Elf3 expression. This suggests Phb1 deletion in ISCs or in goblet cells themselves drives goblet cell abnormalities in $P h b 1^{i \Delta I E C}$ mice that is not recapitulated during Paneth cell-specific Phb1 deletion. Similar to $P h b 1^{i \Delta I E C}$ mice, $P h b 1^{i \text { Mist } 1 \triangle P C}$ mice developed Paneth cell defects and the appearance of intermediate cells at a time point (1 week) prior to normal turnover of Paneth cells (every 30-60 days ${ }^{22}$ ). This suggests that mitochondrial dysfunction in Paneth cells could trigger Paneth cell-intrinsic dedifferentiation to intermediate cells. Alternatively, death of Paneth cells could be accelerated in the Phb1 deficient mice and as a repair response, an ISC-derived effect could give rise to intermediate cells. Given the close proximity of Paneth cells and ISCs and the known interrelationship of Paneth cell mitochondrial metabolism and ISC niche homoeostasis, ${ }^{42}$ loss of Phb1 in Paneth cells could in turn signal to alter ISC differentiation response. Future studies using reporter mice will elucidate whether Paneth cells or ISCs trigger altered IEC differentiation during loss of $P h b 1$.

In summary, our findings further our understanding of intestinal homoeostasis originating at the cellular (Paneth cell) level and organellar (mitochondria) level. We identify Paneth cells as highly susceptible to mitochondrial dysfunction driven by Phb1 deletion and central to the development of ileitis. Treatment of Paneth cell defects with Mito-Tempo during Phb1 deletion implicates a potential therapeutic application for abnormal Paneth cells via elimination of mtROS. Mitochondrial-targeted therapeutics may have translational utility in a subset of patients with Crohn's disease exhibiting Paneth cell defects. These are the first results presenting a causative role of mitochondrial dysfunction in ileitis that initiates in Paneth cells.

\section{MATERIALS AND METHODS}

Materials and methods are included in the online supplementary materials.

\author{
Author affiliations \\ 'Department of Medicine, Baylor Scott and White Research Institute, Dallas, Texas, \\ USA \\ ${ }^{2}$ Veterans Affairs North Texas Health Care System, Dallas, Texas, USA \\ ${ }^{3}$ University of Texas Southwestern Medical Center at Dallas, Dallas, Texas, USA \\ ${ }^{4}$ Gastroenterology and Hepatology, Veteran Affairs North Texas Health Care System, \\ Dallas, Texas, USA \\ ${ }^{5}$ Department of Medicine, Baylor Scott and White Center for Esophageal Research, \\ Dallas, Texas, USA \\ ${ }^{6}$ Internal Medicine, Washington University in Saint Louis School of Medicine, Saint \\ Louis, Missouri, USA \\ ${ }^{7}$ Brigham and Womens Hospital, Boston, Massachusetts, USA \\ ${ }^{8}$ Morehouse School of Medicine, Atlanta, Georgia, USA
}

Acknowledgements We thank Jie Han and Arwa S Kathiria for technical assistance and Beth Cook for histology processing (Baylor Scott \& White Research Institute). We are grateful to P Kay Lund and Amanda Mah (University of North Carolina at Chapel Hill, NC) for assistance with enteroid culturing. We thank Ricardo Olivarez and Stephanie Kara at the Anatomic Pathology Laboratory at Children's Health Medical Centre Dallas, Texas, USA, for assistance with electron microscopy.

Contributors Study concept and design: TD, LAF, RFS, RSB, KV and ALT. Acquisition of data: DNJ, MP, WLN, KT, LT-S and ALT. Analysis and interpretation of data: MP, WLN, KT, BLC, LT-S, KV and ALT. Drafting the manuscript: DNJ, MP and ALT. Critical revision of the manuscript for important intellectual content: TD, LAF, RFS, JCM, RSB, KV and WET.

Funding This work was supported by National Institutes of Health grants R01DK117001 (ALT), R01-DK105129 (JCM), R01-DK088199 (RSB), R03-DK098229 (ALT) and Litwin IBD Pioneers Crohn's Colitis Foundation 301869 (ALT).

Competing interests None declared.

Patient and public involvement Patients and/or the public were not involved in the design, or conduct, or reporting, or dissemination plans of this research.

Patient consent for publication Not required.

Ethics approval Baylor Scott \& White Research Institute Institutional Animal Care and Use Committee.

Provenance and peer review Not commissioned; externally peer reviewed.

Data availability statement All data relevant to the study are included in the article or uploaded as online supplementary information. All mice described in this study must be obtained through an MTA.

Open access This is an open access article distributed in accordance with the Creative Commons Attribution Non Commercial (CC BY-NC 4.0) license, which permits others to distribute, remix, adapt, build upon this work non-commercially, and license their derivative works on different terms, provided the original work is properly cited, appropriate credit is given, any changes made indicated, and the use is non-commercial. See: http://creativecommons.org/licenses/by-nc/4.0/.

\section{ORCID iDs}

Themistocles Dassopoulos http://orcid.org/0000-0003-2968-0321

Rhonda F Souza http://orcid.org/0000-0003-3484-2807

Arianne L Theiss http://orcid.org/0000-0003-2862-0933

\section{REFERENCES}

1 Ray K. IBD: the changing epidemiology of IBD. Nat Rev Gastroenterol Hepatol 2017; 14:690.

$2 \mathrm{Kim} \mathrm{DH}$, Cheon JH. Pathogenesis of inflammatory bowel disease and recent advances in biologic therapies. Immune Netw 2017;17:25-40.

3 Liu JZ, van Sommeren S, Huang H, et al. Association analyses identify 38 susceptibility loci for inflammatory bowel disease and highlight shared genetic risk across populations. Nat Genet 2015;47:979-86.

4 Ho G-T, Aird RE, Liu B, et al. MDR1 deficiency impairs mitochondrial homeostasis and promotes intestinal inflammation. Mucosal Immunol 2018;11:120-30.

5 Jackson DN, Theiss AL. Gut bacteria signaling to mitochondria in intestinal inflammation and cancer. Gut Microbes 2019:1-20.

6 Rath E, Moschetta A, Haller D. Mitochondrial function - gatekeeper of intestinal epithelial cell homeostasis. Nat Rev Gastroenterol Hepatol 2018;15:497-516.

7 Boyapati RK, Dorward DA, Tamborska A, et al. Mitochondrial DNA is a proinflammatory damage-associated molecular pattern released during active IBD. Inflamm Bowel Dis 2018;24:2113-22.

8 Rath E, Berger E, Messlik A, et al. Induction of dsRNA-activated protein kinase links mitochondrial unfolded protein response to the pathogenesis of intestinal inflammation. Gut 2012;61:1269-78.

9 Theiss AL, Idell RD, Srinivasan $S$, et al. Prohibitin protects against oxidative stress in intestinal epithelial cells. Faseb J 2007;21:197-206.

10 Nijtmans LG, de Jong L, Artal Sanz M, et al. Prohibitins act as a membrane-bound chaperone for the stabilization of mitochondrial proteins. Embo J 2000;19:2444-51.

11 Hsieh S-Y, Shih T-C, Yeh C-Y, et al. Comparative proteomic studies on the pathogenesis of human ulcerative colitis. Proteomics 2006;6:5322-31.

12 Theiss AL, Laroui $\mathrm{H}$, Obertone TS, et al. Nanoparticle-based therapeutic delivery of prohibitin to the colonic epithelial cells ameliorates acute murine colitis. Inflamm Bowel Dis 2011;17:1163-76.

13 Theiss AL, Vijay-Kumar M, Obertone TS, et al. Prohibitin is a novel regulator of antioxidant response that attenuates colonic inflammation in mice. Gastroenterology 2009;137:199-208.

14 McClung JK, Jupe ER, Liu XT, et al. Prohibitin: potential role in senescence, development, and tumor suppression. Exp Gerontol 1995;30:99-124.

15 Hedin CR, McCarthy NE, Louis P, et al. Altered intestinal microbiota and blood T cell phenotype are shared by patients with Crohn's disease and their unaffected siblings. Gut 2014;63:1578-86.

16 Mondot S, Kang S, Furet JP, et al. Highlighting new phylogenetic specificities of Crohn's disease microbiota. Inflamm Bowel Dis 2011;17:185-92.

17 Colbourne F, Sutherland GR, Auer RN. Electron microscopic evidence against apoptosis as the mechanism of neuronal death in global ischemia. J Neurosci 1999;19:4200-10.

18 Artal-Sanz M, Tavernarakis N. Prohibitin couples diapause signalling to mitochondrial metabolism during ageing in C. elegans. Nature 2009;461:793-7.

19 Liu D, Lin Y, Kang T, et al. Mitochondrial dysfunction and adipogenic reduction by prohibitin silencing in 3T3-L1 cells. PLoS One 2012;7:e34315. 
20 Rath E, Haller D. Mitochondria at the interface between danger signaling and metabolism: role of unfolded protein responses in chronic inflammation. Inflamm Bowel Dis 2012;18:1364-77.

21 Liu Q, Zhang D, Hu D, et al. The role of mitochondria in NLRP3 inflammasome activation. Mol Immunol 2018;103:115-24.

22 Clevers HC, Bevins CL. Paneth cells: maestros of the small intestinal crypts. Annu Rev Physiol 2013;75:289-311.

23 Cadwell K, Liu JY, Brown SL, et al. A key role for autophagy and the autophagy gene Atg16l1 in mouse and human intestinal Paneth cells. Nature 2008;456:259-63.

24 Cadwell K, Patel KK, Maloney NS, et al. Virus-plus-susceptibility gene interaction determines Crohn's disease gene Atg16L1 phenotypes in intestine. Cell 2010;141:1135-45.

25 Liu T-C, Gao F, McGovern DPB, et al. Spatial and temporal stability of paneth cell phenotypes in Crohn's disease: implications for prognostic cellular biomarker development. Inflamm Bowel Dis 2014;20:646-51.

26 Liu T-C, Gurram B, Baldridge MT, et al. Paneth cell defects in Crohn's disease patients promote dysbiosis. JCl Insight 2016;1:e86907.

27 VanDussen KL, Liu T-C, Li D, et al. Genetic variants synthesize to produce paneth cell phenotypes that define subtypes of Crohn's disease. Gastroenterology 2014;146:200-9.

28 Stahl M, Tremblay S, Montero M, et al. The MUC2 mucin coats murine Paneth cell granules and facilitates their content release and dispersion. Am J Physiol Gastrointest Liver Physio/ 2018:315:G195-205.

29 Yang Q, Bermingham NA, Finegold MJ, et al. Requirement of Math1 for secretory cell lineage commitment in the mouse intestine. Science 2001:294:2155-8.

30 Dikalova AE, Bikineyeva AT, Budzyn K, et al. Therapeutic targeting of mitochondrial superoxide in hypertension. Circ Res 2010;107:106-16.
31 Aytekin FO, Teke Z, Aydin C, et al. Effects of a membrane-permeable radical scavenger tempol, on healing of colonic anastomoses in the cecal ligation and puncture model of polymicrobial sepsis in rats. Am J Surg 2007;193:723-9.

32 Lo H-YG, Jin RU, Sibbel G, et al. A single transcription factor is sufficient to induce and maintain secretory cell architecture. Genes Dev 2017;31:154-71.

33 Kugathasan S, Denson LA, Walters TD, et al. Prediction of complicated disease course for children newly diagnosed with Crohn's disease: a multicentre inception cohort study. Lancet 2017:389:1710-8.

34 Mottawea W, Chiang C-K, Mühlbauer M, et al. Altered intestinal microbiota-host mitochondria crosstalk in new onset Crohn's disease. Nat Commun 2016;7:13419.

35 Vidrich A, Buzan JM, Barnes S, et al. Altered epithelial cell lineage allocation and global expansion of the crypt epithelial stem cell population are associated with ileitis in SAMP1/YitFc mice. Am J Pathol 2005;166:1055-67.

36 Chowdhury D, Kumar D, Sarma P, et al. PHB in cardiovascular and other diseases: present knowledge and implications. Curr Drug Targets 2017:18:1836-51.

37 Adolph TE, Tomczak MF, Niederreiter L, et al. Paneth cells as a site of origin for intestinal inflammation. Nature 2013:503:272-6.

38 Berger E, Rath E, Yuan D, et al. Mitochondrial function controls intestinal epithelial stemness and proliferation. Nat Commun 2016;7:13171.

39 Katz JP, Perreault N, Goldstein BG, et al. The zinc-finger transcription factor KLF4 is required for terminal differentiation of goblet cells in the colon. Development 2002:129:2619-28.

40 Nowarski R, Jackson R, Gagliani N, et al. Epithelial IL-18 equilibrium controls barrier function in colitis. Cell 2015:163:1444-56.

41 Pu Z, Che Y, Zhang W, et al. Dual roles of IL-18 in colitis through regulation of the function and quantity of goblet cells. Int J Mol Med 2019:43:2291-302.

42 Rodríguez-Colman MJ, Schewe M, Meerlo M, et al. Interplay between metabolic identities in the intestinal crypt supports stem cell function. Nature 2017:543:424-7. 